\title{
Ganglioside GD3 Is Required for Neurogenesis and Long- Term Maintenance of Neural Stem Cells in the Postnatal Mouse Brain
}

\author{
Jing Wang, ${ }^{1,4}$ Allison Cheng, ${ }^{1}$ Chandramohan Wakade, ${ }^{3,4}$ and Robert K. Yu ${ }^{1,2,4}$ \\ ${ }^{1}$ Department of Neuroscience and Regenerative Medicine, Medical College of Georgia, ${ }^{2}$ Department of Neurology, Medical College of Georgia, and \\ ${ }^{3}$ Department of Physical Therapy, College of Allied Health Science, Georgia Regents University, Augusta, Georgia 30912, and ${ }^{4}$ Charlie Norwood VA Medical \\ Center, Augusta, Georgia 30904
}

\begin{abstract}
The maintenance of a neural stem cell (NSC) population in mammalian postnatal and adult life is crucial for continuous neurogenesis and neural repair. However, the molecular mechanism of how NSC populations are maintained remains unclear. Gangliosides are important cellular membrane components in the nervous system. We previously showed that ganglioside GD3 plays a crucial role in the maintenance of the self-renewal capacity of NSCs in vitro. Here, we investigated its role in postnatal and adult neurogenesis in GD3-synthase knock-out (GD3S-KO) and wild-type mice. GD3S-K0 mice with deficiency in GD3 and the downstream b-series gangliosides showed a progressive loss of NSCs both at the SVZ and the DG of the hippocampus. The decrease of NSC populations in the GD3S-KO mice resulted in impaired neurogenesis at the granular cell layer of the olfactory bulb and the DG in the adult. In addition, defects of the self-renewal capacity and radial glia-like stem cell outgrowth of postnatal GD3S-KO NSCs could be rescued by restoration of GD3 expression in these cells. Our study demonstrates that the b-series gangliosides, especially GD3, play a crucial role in the long-term maintenance NSC populations in postnatal mouse brain. Moreover, the impaired neurogenesis in the adult GD3S-KO mice led to depression-like behaviors. Thus, our results provide convincing evidence linking b-series gangliosides deficiency and neurogenesis defects to behavioral deficits, and support a crucial role of gangliosides in the long-term maintenance of NSCs in adult mice.
\end{abstract}

Key words: depression; EGFR; ganglioside; genetic model; membrane microdomain; radial glial cell

\section{Introduction}

Neural stem cells (NSCs) are known to maintain the neurogenesis potential of the mammalian brain throughout life by increasing their capability for proliferation and/or survival in response to stimuli and environmental demands (Buffo et al., 2008). In the adult brain, NSCs are primarily located in two regions: the SVZ of the lateral ventricle and the subgranular zone (SGZ) of the DG (Zhao et al., 2008). A decrease of neurogenesis can be involved in defects of olfactory learning (Alonso et al., 2006), hippocampus-dependent behavioral changes (Snyder et al., 2011), and declines in pattern separation ability (Aimone et al., 2011). How the neurogenesis capacity of these NSCs in vivo is regulated and how the NSC pools are maintained in adult brains are still not completely understood.

\footnotetext{
Received June 3, 2014; revised Aug. 16, 2014; accepted Sept. 2, 2014.

Author contributions: J.W. and R.K.Y. designed research; J.W., A.C., C.W., and R.K.Y. performed research; R.K.Y. contributed unpublished reagents/analytic tools; J.W., A.C., and R.K.Y. analyzed data; J.W. and R.K.Y. wrote the paper.

This work was supported in part by grants from the National Institutes of Health and Veterans Administration. We thank Dr. Richard Cameron, Georgia Regents University, Augusta, GA, for his invaluable suggestions in preparing this manuscript.

The authors claim no conflict of interest.

Correspondence should be addressed to Robert K. Yu, PhD, Department of Neuroscience and Regenerative Medicine, Medical College of Georgia, Georgia Regents University, Augusta, GA 30912. E-mail: ryu@gru.edu.

DOI:10.1523/JNEUROSCI.2275-14.2014

Copyright $\odot 2014$ the authors $\quad 0270-6474 / 14 / 3413790-11 \$ 15.00 / 0$
}

Gangliosides are sialic acid-containing glycosphingolipids, which are most abundant in the nervous system (Yu et al., 2009). Because of their specialized localization on the plasma membrane surface, these ganglioside-enriched microdomains (also known as lipid rafts) have been proposed to be important for modulation of signaling transduction (Allen et al., 2007) and cell adhesion (Hakomori et al., 1998). However, the roles of these specialized microdomains in neurogenesis remain largely unknown. NeuAc $\alpha 2-8$ NeuAc $\alpha 2-3$ Gal $\beta 1-4$ Glc- $\beta 1-1^{\prime}$ Cer; CD60a (GD3) is a $\mathrm{b}$-series disialoganglioside that has long been characterized as a marker of immature neuroectodermal cells (Goldman et al., 1984). Its level of expression in brains rapidly decreases soon after birth, and is no longer detectable after NSCs undergo differentiation (Nakatani et al., 2010). By studying in vitro NSC cultures, we previously showed that GD3, in association with EGF receptors, played a crucial role in maintaining the self-renewal capability of NSCs (Wang and Yu, 2013). Moreover, the cell-surface localization of GD3 on NSCs also places it as a component of the membrane microdomains that process signaling in response to extrinsic stimuli. To clarify the role of GD3 in the maintenance of NSCs and neurogenesis in vivo, we investigated the loss-of-function role of GD3 in the developing and adult GD3-synthase KO (GD3S-KO) mouse brains in comparison with their WT littermates.

In the present study, we observed impaired neurogenesis capacity in the adult GD3S-KO mice. This neurogenesis deficit was 
accompanied by a progressive decrease of the NSC pool in adult GD3S-KO mouse brains, which may be due to the defective selfrenewal capacity of the NSCs. Furthermore, we demonstrated for the first time that the adult GD3S-KO mice showed depressionlike behaviors characterized by increased immobility time and decreased latency to immobility during the tail-suspension test (TST) and forced-swim test (FST). These behavior deficits are very likely the result of impaired neurogenesis in these mice. Our results thus indicate that b-series gangliosides, especially GD3, are required for maintaining the NSC pool and neurogenesis in the late postnatal and adult mouse brain and that deficiency in these gangliosides may result in neurogenesis deficits and behavioral changes.

\section{Materials and Methods}

Animals. The original GD3S-KO mice and their WT mates were kindly provided by the courtesy of Dr. Richard Proia (NIDDK, NIH, Bethesda, $\mathrm{MD}$ ) and crossed to generate the heterozygous mice. Then, the heterozygous male and female mice were mated, and PCR screening was performed for genotyping. Littermates were used as controls. E16 and P2 pups were used for embryonic neurogenesis and neurodevelopmental study; 1- and 6-month-old WT and homozygous KO mice were used for the adult neurogenesis study. NSCs were obtained from brains of P10 pups. For each experiment, at least four pairs (two males and two females) of gender-matched animals were used for comparison. For the behavioral studies, 10 pairs (4 males and 6 females) of gender-matched mice were tested. All experiments with mice were performed within the guidelines of the Laboratory Animal Services and Institutional Animal Care and Use Committee of Georgia Regents University.

NSC culture and radial glia-like cell outgrowth assay. Neurospheres were prepared with tissues from SVZs of postnatal mouse (P10) as described previously (Wang and $\mathrm{Yu}, 2013$ ). In brief, tissues dissected from mouse SVZ were dissociated into a single-cell suspension by TrypLE Express at $37^{\circ} \mathrm{C}$ for $10 \mathrm{~min}$. The obtained single-cell suspensions were grown in Neurobasal-A medium (Life Technologies) supplemented with B27 (Life Technologies), 2 mm L-glutamine (Life Technologies), bFGF (20 ng/ml; PeproTech), and EGF (20 ng/ml; PeproTech). Secondary neurospheres were cultured by dissociation of 7 DIV primary neurospheres with TrypLE Express into single cells, which were then resuspended at $10,000 \mathrm{cell} / \mathrm{ml}$. For radial glia-like cell outgrowth analysis, neurospheres or cell clusters growing for $5 \mathrm{~d}$ were plated onto poly-L-ornithine (PLO; $15 \mu \mathrm{g} / \mathrm{ml}$, Sigma-Aldrich) and fibronectin-coated ( $1 \mu \mathrm{g} / \mathrm{ml}$; SigmaAldrich) plates for $48 \mathrm{~h}$. The outgrowth of radial glia-like cells was monitored by the radial glia-like morphology and further analyzed by immunostaining of GFAP and nestin. For restoration of GD3 expression in the GD3S-KO NSCs, a pEGFP-N1 vector containing ST-II cDNA or the vector only (used as control) was electrotransfected into single cells dissociated from the primary spheres using a Mouse NSC Nucleotransfector Kit (Amaxa). Dissociated cells were seeded onto PLO- and fibronectin-coated coverslips for analysis of transfection efficiency and restoration of GD3 expression by immunostaining after $24 \mathrm{~h}$. Other dissociated cells were resuspended in neurosphere growth medium for neurosphere formation and radial glia-like cell outgrowth assay.

BrdU incorporation assay and immunohistochemistry. For a short-term BrdU incorporation assay, BrdU was administrated intraperitoneally at $50 \mathrm{mg} / \mathrm{kg}$ three times at $4 \mathrm{~h}$ intervals followed by $4 \%$ PFA perfusion $16 \mathrm{~h}$ after the last injection. For a long-term BrdU lineage tracing assay, animals were killed at 4 weeks after BrdU administration. Postfixation was performed for $16 \mathrm{~h}$ at $4^{\circ} \mathrm{C}$ using $4 \%$ PFA. Brain blocks containing SVZ or hippocampal region were embedded in optimal cutting temperature compound and frozen in liquid nitrogen, and then cryosectioned at a thickness of $20 \mu \mathrm{m}$. For immunostaining, sections were incubated in $2 \mathrm{~N} \mathrm{HCl}$ for $30 \mathrm{~min}$ at $37^{\circ} \mathrm{C}$ and washed with PBS before addition of BrdU antibody (mouse, 1:200; Developmental Studies Hybridoma Bank, G3G4). The samples were then subjected to the procedures for immunohistochemistry.

Immunocytochemistry, immunohistochemistry, and confocal microscopy. Cryosections or cells were blocked in 3\% normal donkey serum in
PBS with/without $0.3 \%$ Triton X-100 for $60 \mathrm{~min}$. The brain sections or cells were then incubated in a blocking solution containing the primary antibodies at $4^{\circ} \mathrm{C}$ overnight. After three washes with PBS, the samples were incubated in secondary antibodies coupled to Alexa 488, Alexa 568, or Alexa 647 (Invitrogen) at a dilution of 1:1000 at room temperature for $1 \mathrm{~h}$. After washing with PBS three times, the samples were mounted with Vectashield mountain medium with/without DAPI (Vector Laboratories). Anti-GD3 mAb R24 (1:100) was kindly provided by Dr. Ken Lloyd (Memorial Sloan Kettering Cancer Center, New York, NY). The other primary antibodies used were listed as follows: radial glial cell marker (mouse, 1:100; Developmental Studies Hybridoma Bank, RC2), DCX (goat, 1:200; Santa Cruz Biotechnology, C-18), GFAP (mouse, 1:500; Sigma G-3893), GFAP (rabbit, 1:500; Dako z-0334), SOX2 (rabbit, 1:100; Cell Signaling Technology, \#2748), nestin (mouse, 1:200; BD Bioscience PharMingen, 556309), nestin (rabbit, 1:200; Abcam, ab27952), Ki-67 (rabbit, 1:200; EMD Millipore, AB9260) and NeuN (rabbit, 1:1000; Millipore, \#ABN78). Controls were performed using appropriate secondary antibodies only as indicated above. Confocal images were obtained using a Zeiss LSM 510 META confocal microscope. Pictures were taken under a $20 \times, 40 \times$, or $63 \times$ Plan-Apochromat objective. The number of $\mathrm{BrdU}^{+}$, $\mathrm{SOX}_{2}{ }^{+}, \mathrm{SOX}_{2}{ }^{+} \mathrm{GFAP}^{+}$, and $\mathrm{NeuN}^{+}$cells in the SVZ and DG was determined by double-blind counting with ImageJ software. DAPI staining was used to trace the DG cellularity, and NeuN staining was used to measure the neurons of the inner granular cell layers (GCLs). At least four pairs of gender-matched animals were measured for each staining. From each pair of mice, $20 \mu \mathrm{m}$ sections of SVZ (50 sections) and dorsal hippocampus (30 sections) were collected, and the one representative section from each five successive sections was chosen for counting and measurement. At least five sections were counted for each measurement. Data are presented as mean \pm SEM, and analyses of significant difference were performed using two-tailed unpaired Student's $t$ test. A $p$ value of $<0.05$ was considered significant: ${ }^{\star} p<0.05 ;{ }^{* *} p<0.01$

Behavioral studies. In the TST, mice were suspended by their tails from a horizontal bar using adhesive tape. Climbstoppers were placed around the tails before applying the tape. The recording was taken once the first piece of tape was applied. At the end of the session (6 min), animals returned to their home cages and the tape was carefully removed from the tails by gently pulling it off. During the behavioral analysis, the time that each mouse spent as mobile was measured using a time-sampling technique. The movements that were recorded as bona fide mobility included attempts trying to reach the walls of the apparatus and the suspension bar, strong shaking of the body, and movement of limbs akin to running. For the FST, mice were individually placed in a Plexiglas cylinder $(19 \mathrm{~cm}$ diameter, $30 \mathrm{~cm}$ height) containing water at a $19 \mathrm{~cm}$ height $\left(23 \pm 1^{\circ} \mathrm{C}\right)$ and were videotaped for $6 \mathrm{~min}$. After the swimming session, mice were dried and placed in a cage surrounded by a heating pad. Water was changed between each animal being tested. The video files of each recording session were uploaded from the camera to a computer. The active (swimming, climbing, and struggling) or passive (immobility) behaviors were scored using a time sampling technique. For both tests, the total immobility time was calculated by $360 \mathrm{~s}$ minus the time of mobility. The time for each mouse to come to the first immobility (the latency to immobility) was also measured. Nine to 10 pairs of gender-matched animals were recorded and measured for each test. Data are presented as mean \pm SEM, and analyses of significant difference were performed using two-tailed unpaired Student's $t$ test. A $p$ value of $<0.05$ was considered significant: ${ }^{\star} p<0.05 ;{ }^{\star *} p<0.01$.

\section{Results}

\section{Histological expression of GD3 at SVZ and DG in postnatal and adult mouse brain}

Ganglioside GD3 is known to be highly expressed in embryonic brains, but its concentration is rapidly reduced soon after birth (Ngamukote et al., 2007). To understand the significance of GD3 in neurogenesis, we first analyzed the expression profile of GD3 by immunostaining the SVZ and DG, the two major regions where NSCs reside in postnatal and adult mouse brains. In the brains of P2 mice, GD3 expression was mostly detected at the 
A

A $\quad$ SVZ (P2)

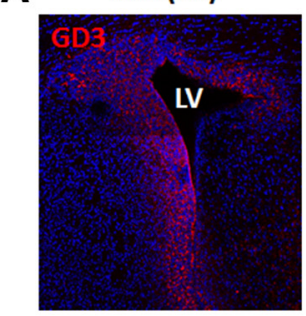

C
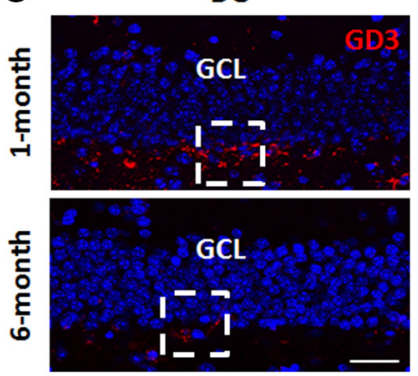

Hippocampus (P2)

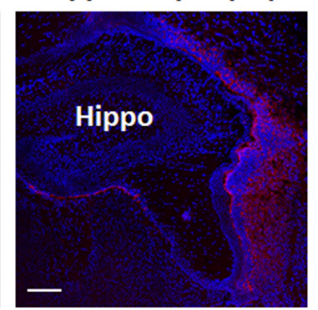

Zoom

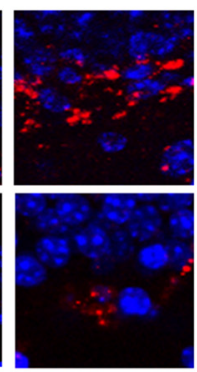

B
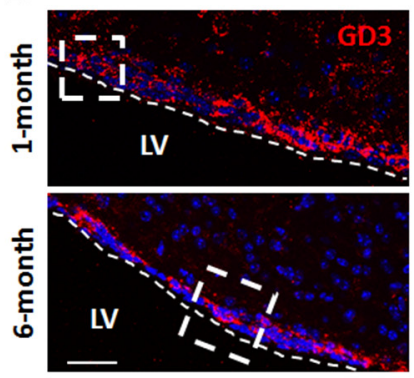

D

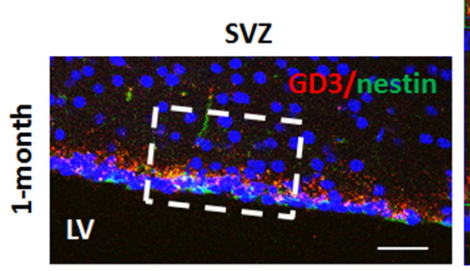

Zoom

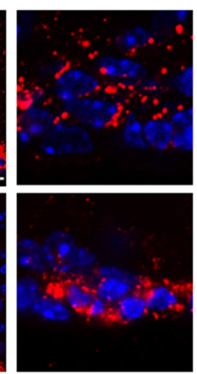

Zoomed and Z-stack

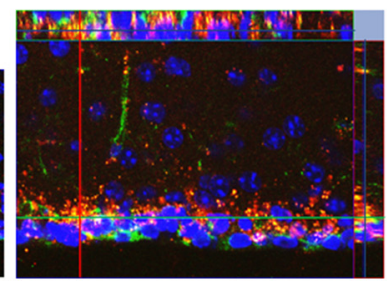

Figure 1. Histological expression of GD3 in the SVZ and hippocampus of postnatal and adult mouse brains. $A$, Immunofluorescence staining of GD3 in the SVZ and hippocampus of P2 mouse brain. $B, C$, Immunofluorescence staining of GD3 in SVZ (B) and DG $(\boldsymbol{C})$ of 1 - and 6-month-old brains. The zoomed areas are shown enlarged on the right. $D$, Coexpression of GD3 with nestin in cells of the SVZ from 1-month-old mouse brain. LV, lateral ventricle; Hippo, hippocampus. Scale bars: $A, 100 \mu \mathrm{m} ; \boldsymbol{B}, \boldsymbol{C}, \boldsymbol{D}, 50 \mu \mathrm{m}$.

SVZ and its surrounding regions (Fig. 1A). In the adult stages, the expression of GD3 was detected at the SVZ from both 1- and 6-month-old brains of WT mice; however, the expression level was reduced in the 6-month-old brain compared with that in the 1-month-old brain (Fig. 1B). In DG, the expression of GD3 was detected at the SGZ of 1-month-old mice; however, in 6-monthold mice, very few GD3-positive cells could be detected at the SGZ (Fig. 1C). Moreover, in the individual cells, the GD3 staining showed a punctate-like pattern surrounding the nuclei, which was consistent with the GD3 expression pattern found by staining the in vitro cultured NSCs (Wang and Yu, 2013). Double labeling of GD3 with nestin showed the coexpression of GD3 with nestin in cells in the SVZ of WT mouse brain (Fig. 1D). This observation further confirmed the expression of GD3 in the NSCs of adult mouse brain in vivo. No GD3-positive staining was detected in the GD3S-KO brain sections (data not shown). The reduced GD3 expression in the SVZ and DG where NSCs reside was correlated to the decreased number and reduced neurogenesis capability of NSCs in these regions during aging. The result suggests a role of GD3 as a marker and regulator of the postnatal NSC pool in vivo.

\section{Reduced cellularity in SVZ and DG of adult GD3S-KO mice}

Previously, our in vitro study showed reduced self-renewal ability of NSCs from embryonic and postnatal GD3S-KO mice, and the reduction was found to be greater with further passages (Wang and $\mathrm{Yu}, 2013$ ). These observations imply that GD3 plays a greater role in the maintenance, rather than the generation, of NSCs. However, the high concentration of GD3 in developing mouse brain during E12-E14 also suggests a role for GD3 in neurodevelopment (Ngamukote et al., 2007). To investigate the potential role of GD3 in neurodevelopment and early postnatal neurogenesis, we first assessed the NSC population and neurodevelopment of GD3S-KO mice in E16 and early postnatal (P2) stages. It has been shown that radial glial cells (RC2 positive) represent the main population of neural progenitors of developing brain in the embryonic stage (Malatesta et al., 2003), and they give rise to neurons in many regions of the CNS (Anthony et al., 2004). In late embryonic and postnatal stages, radial glial cells give rise to adult NSCs that continue to produce neurons throughout life (Merkle et al., 2004). These adult NSCs lose their RC2 expression, but are mostly GFAP positive with a typical radial glia-like morphology. Therefore, we examined the NSC population in E16 by RC2 immunostaining and in P2 by nestin and GFAP costaining.

In developing embryonic brains, e.g., E16, we did not detect any significant difference in the number of radial glial cells (RC2 positive) between WT and GD3S-KO mice (Fig. 2A). In the P2 brain sections, the number of GFAP and nestin double-positive cells in the SVZ and DG regions was comparable between the WT and GD3S-KO mice (Fig. 2B). The number of dividing cells (Ki67-positive cells) at this stage did not show any significant differences either at the SVZ (GD3S-KO 244.0 \pm 53.7 vs WT $251.8 \pm 25.9, p>0.05)$ or at the DG (GD3S-KO $256.0 \pm 18.5 \mathrm{vs}$ WT $232.6 \pm 23.5, p>0.05$ ) regions (Fig. $2 C$ ). To this end, we found that the NSC populations and neurogenesis of GD3S-KO mice were almost normal in SVZ and DG at the embryonic and early postnatal stages.

To investigate the maintenance of postnatal and adult NSC populations in the GD3S-KO mice, we examined the histology and cellularity of SVZ and DG in early (1-month-old) and late (6-month-old) adult GD3S-KO mice in comparison with their WT littermates. In GD3-KO mice, both 1- and 6-month-old brains showed a thinner SVZ with reduced cellularity compared with their WT littermates (cellularity of SVZ at 1 month: GD3S-KO 158.4 \pm 6.1 vs WT $273.7 \pm 17.7, p<0.01$; cellularity of SVZ at 6 months: GD3S-KO 84.9 \pm 3.1 vs WT $163.3 \pm 6.6, p<$ 0.01 ; Fig. $3 A-C)$. The cellularity of DG showed no significant difference between WT and GD3S-KO in 1-month-old mice $($ GD3S-KO $1939.0 \pm 163.5$ vs WT $2183.0 \pm 110.8, p>0.05)$; however, the number of cells in the DG of 6-month-old GD3S-KO mice was significantly reduced compared with that of their WT littermates (GD3S-KO $969.5 \pm 89.9$ vs $1562.0 \pm 61.3$, $p<0.01$; Fig. $3 A, B, D)$. These findings indicated that there was a progressive reduction of cellular pool in the SVZ of early and late adult GD3S-KO mice. The comparable size and cellularity at DG between WT and GD3S-KO at 1 month of age revealed that the neurodevelopmental changes caused by GD3 deficiency in em- 
A

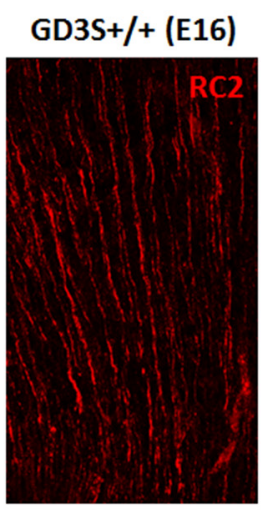

GD3S-/- (E16)

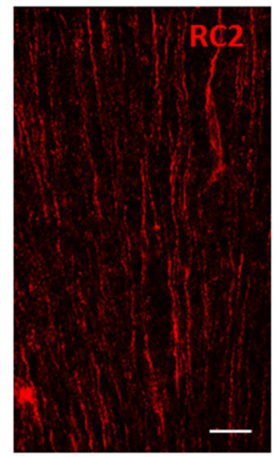

B
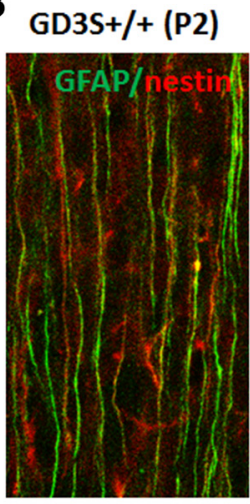

C
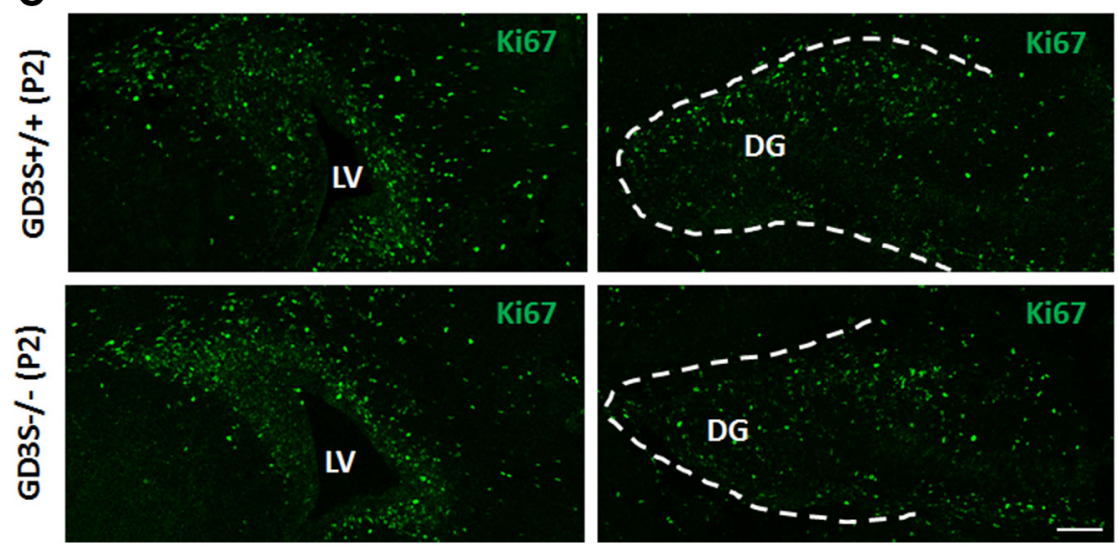

Figure 2. NSC population and neurogenesis in embryonic and early postnatal GD3S-KO mice are grossly normal. $\boldsymbol{A}$, Immunostaining for RC2 to examine the radial glial cells in developing brains at E16. $\boldsymbol{B}$, Coimmunostaining for Nestin and GFAP to observe the postnatal radial glia-like cells in early postnatal (P2) brain sections. Shown here are the representative regions between SVZ and cerebral cortex, where the newborn neurons migrate to the cerebral cortex presumably under the guidance of radial glia-like cells. C, Immunostaining for Ki67 to measure the proliferating cell population in P2 brain sections in SVZ and DG. LV, lateral ventricle. Scale bars: $50 \mu \mathrm{m}$.

bryonic and early postnatal ages were not obvious. It has been shown that after the proliferation and differentiation of NSCs, newborn neurons of the adult SGZ will eventually migrate to the inner GCL of DG and become dentate granule neurons (Kuhn et al., 1996; Zhao et al., 2006). Therefore, the decrease of DG cellularity in 6-month-old GD3S-KO mice is consistent with the notion that defective neurogenesis may occur in the late postnatal and adult stages as a result of GD3 deficiency, and that this defect may be driven by impaired maintenance of the NSC population in the adult GD3S-KO mouse brain.

\section{Progressive loss of the NSC pool in the SVZ of GD3S-KO mice in adulthood}

To test the above hypothesis and further examine the role of GD3 in adult neurogenesis and in maintaining the NSC population, BrdU incorporation and the expression of endogenous NSC markers were measured in the WT and GD3S-KO mouse brain. At the SVZ of 1-month-old mouse brain, the number of BrdUincorporated cells was reduced in the GD3S-KO mice compared with their WT littermates (GD3S-KO 97.2 \pm 5.3 vs WT $169.8 \pm$ 8.5 per section, $p<0.01$; Fig. $4 A, C$ ). At 6 months of age, the decrease in the number of BrdU-incorporated cells in the SVZ of the GD3S-KO mice was even more pronounced (GD3S-KO $17.8 \pm 2.7$ vs WT $87.6 \pm 7.1$ per section, $p<0.001$; Fig. $4 B, C$ ). As BrdU incorporates into dividing cells during DNA synthesis, the actively dividing NSCs or the transient-amplifying progenitors

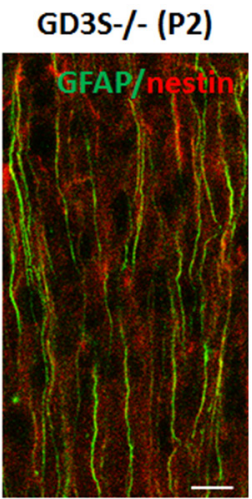

cannot be distinguished by this labeling. Nonetheless, the reduction of BrdUpositive cells implies a progressive loss of neurogenesis capacity in the GD3S-KO mice, consistent with our previous observations by cellularity analysis (Fig. 3). Similarly, the number of SOX2-positive cells was also reduced in the SVZ of the GD3S-KO mice compared with that in the WT mice at both 1 month (GD3S-KO $163.8 \pm 10.5$ vs WT $361.1 \pm 8.6$ per section $p<0.01)$ and 6 months of age (GD3S-KO $129.8 \pm 12.2$ vs WT $289.6 \pm$ 21.2 per section, $p<0.01$; Fig. $4 A, B, D)$. This observation indicates that the reduction of the SOX2-positive NSC cell population in the GD3S-KO mice occurs as early as 1 month of age. This reduction continues as the mice grow older, and might be responsible for the progressive reduction of the proliferating cell population in the GD3S-KO mice.

Continuous neurogenesis throughout life depends on a tight balance of NSC maintenance, proliferation, and differentiation, and the adult NSCs are believed to be largely quiescent or slowly dividing (Doetsch et al., 1999; Seri et al., 2001). Therefore, the decreased proliferating cell population can also result from a proliferation defect caused by failure to enter the cell cycle. If only the proliferation of GD3S-KO NSCs was hindered, this would result in an accumulation or unchanged number of quiescent NSCs at the SVZ. To test this possibility, we counted the nestin and GFAP doublepositive (nestin ${ }^{+} \mathrm{GFAP}^{+}$) radial glia-like NSC population in the brain. The nestin-expressing radial glia-like cells have been shown to be largely quiescent NSCs residing in the adult brain (Bonaguidi et al., 2011). Here, we found that the nestin ${ }^{+} \mathrm{GFAP}^{+}$ cells were reduced at the SVZ of 1-month-old GD3S-KO mouse brain $(57.7 \pm 16.2 \%$ of WT; Fig. $4 E)$. In the 6-month-old SVZ, the nestin ${ }^{+}$GFAP $^{+}$cells were nearly absent from the GD3S-KO brains (Fig. 4F). Those observations, together with our finding that the SOX2-positive cells were progressively reduced in the GD3S-KO SVZ, support the conclusion that deficiency of GD3 contributes not only to the decrease of the proliferating cell population, but also the depletion of the NSC pool in the GD3S-KO mouse brain.

It is noteworthy that when the percentage of BrdUincorporated cells (BrdU ${ }^{+} / \mathrm{DAPI}$ ) was measured, no obvious difference of the $\mathrm{BrdU}^{+} / \mathrm{DAPI}$ ratio was detected between GD3S-KO mice and their WT littermates (GD3S-KO $24.9 \pm 3.8$ vs WT $24.2 \pm 2.5 \%, p>0.05)$ at 1 month of age. However, the percentage of SOX2-positive cells (the SOX $2^{+} / \mathrm{DAPI}$ ratio) was reduced in the 1-month-old GD3S-KO mice (GD3S-KO $35.8 \pm$ 1.1 vs WT $46.5 \pm 6.1 \%, p<0.05)$. At 6 months of age, both the $\mathrm{BrdU}^{+} / \mathrm{DAPI}$ and SOX $2^{+} / \mathrm{DAPI}$ ratios in the GD3S-KO mice were greatly reduced (BrdU ${ }^{+} / \mathrm{DAPI}$ : GD3S-KO $4.6 \pm 4.0 \mathrm{vs} \mathrm{WT}$ $18.3 \pm 4.9 \%, p<0.01$; SOX $2{ }^{+} / \mathrm{DAPI}: \mathrm{GD} 3 \mathrm{~S}-\mathrm{KO} 12.4 \pm 3.3$ vs WT $42.6 \pm 2.0 \%, p<0.01)$. The lack of difference in the 
$\mathrm{BrdU}^{+} / \mathrm{DAPI}$ ratio in young adult mice also supported that the progressive loss of proliferating cells in the SVZ did not result from a cell cycle parameter deficiency in the GD3S-KO mice, but more likely was caused by a depletion of the NSC pool from the mouse brain.

Progressive loss of NSC pool in the DG of GD3S-KO mice in adulthood

In the SGZ of DG, the NSCs are classified into two types according to their specific morphologies and expression of unique sets of molecular markers. Type 1 NSCs possess a radial glia-like morphology and express nestin, GFAP, and SOX2; type 2 NSCs only have short processes and do not express GFAP (Zhao et al., 2008). Although it is not clear whether type 2 NSCs arise from type 1 cells, there is evidence showing that type 2 SOX2-positive cells have the ability for self-renewal and give rise to neurons and astrocytes (Suh et al., 2007). Therefore, we examined the NSC population at the DG by SOX2, GFAP, and nestin staining. Type 1 NSCs were measured by the number of SOX2 and GFAP double-positive $\left(\mathrm{SOX}^{+} \mathrm{GFAP}^{+}\right.$) cells, and the SOX2-positive and GFAPnegative $\left(\mathrm{SOX}^{+}{ }^{+} \mathrm{GFAP}^{-}\right)$cells located at the SGZ were counted as type 2 NSCs. In the DG of 1-month-old mouse brain, the number of type 1 NSCs was significantly reduced in the GD3S-KO mice (GD3S-KO $72.8 \pm 8.9$ vs WT $207.3 \pm$ $35.3, p<0.05)$; however, the reduction of type 2 cells was not obvious in this case (GD3S-KO 196.0 \pm 39.0 vs WT, $213.4 \pm$ $43.6, p>0.05$; Fig. $5 A, B$ ). At 6 months of age, both type 1 and type 2 NSCs were reduced in the DG of GD3S-KO mouse brain (type 1: GD3S-KO $66.4 \pm 9.2$ vs WT $135.8 \pm 10.0, p<0.01$; type 2 : GD3S-KO $39.0 \pm 15.4$ vs WT $71.2 \pm 17.4, p<0.01$; Fig. $5 A, C)$.

Consistent with this observation, the nestin and GFAP double-positive $\left(\right.$ nestin ${ }^{+} \mathrm{GFAP}^{+}$) radial glia-like cells at the SGZ of GD3S-KO mice were also significantly reduced compared with their WT littermates. In the 1-month-old brain, the number of nestin ${ }^{+} \mathrm{GFAP}^{+}$cells was reduced by almost 50\% (45.7 \pm $13.6 \%$ ) in the DG of GD3S-KO mouse brain compared with their WT littermates (Fig. 5D). This reduction became more obvious as the mouse grew older. In the brain of 6-month-old animals, the number of nestin ${ }^{+} \mathrm{GFAP}^{+}$cells was reduced by $>80 \%(83.2 \pm 15.2 \%)$ in the DG region of the GD3S-KO mouse brain compared with their WT littermates (Fig. 5E). The reduction of type 1 NSCs and the
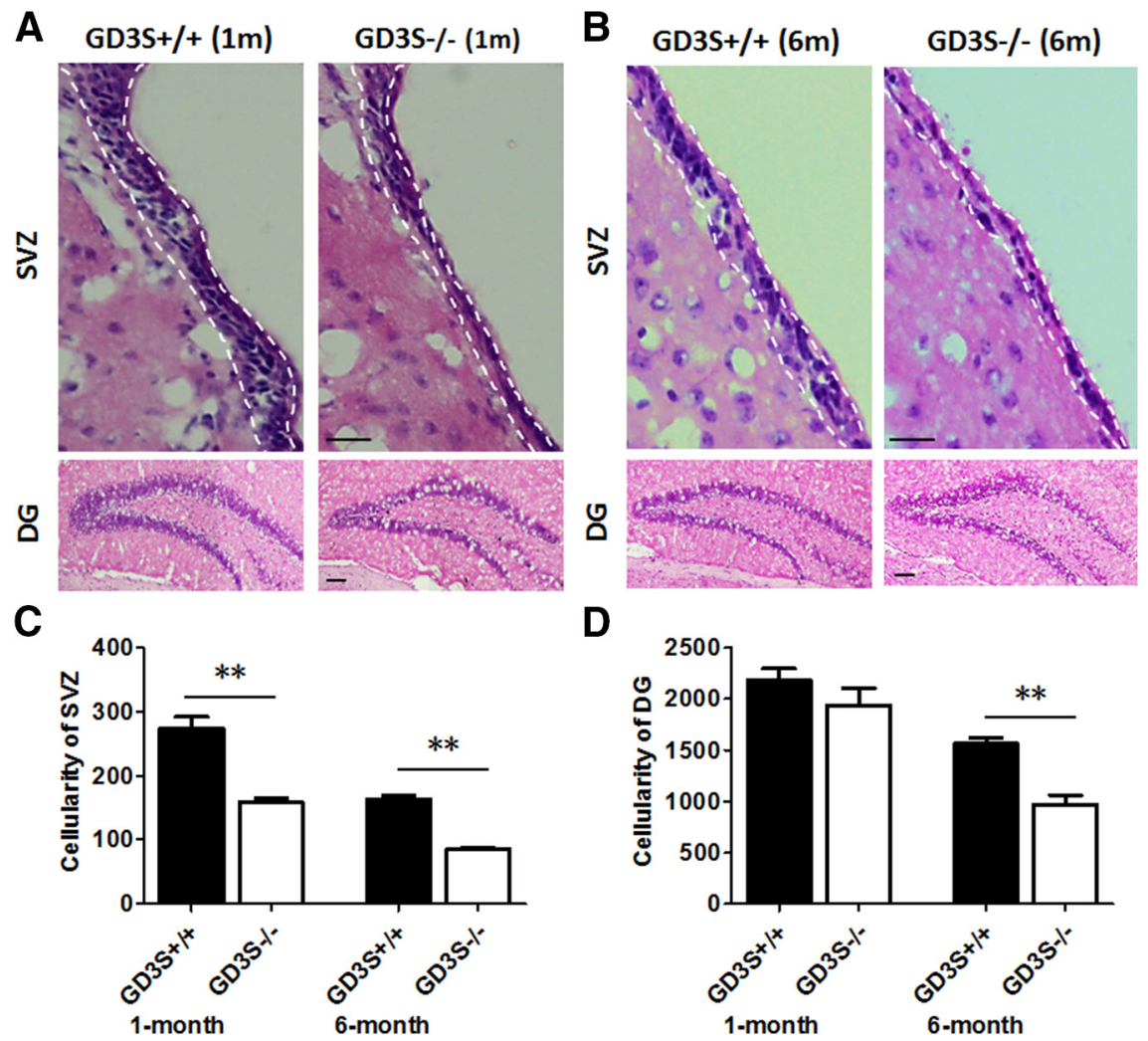

Figure 3. Reduced cellularity in SVZ and DG of adult GD3S-KO mouse brain. $A, B, H \& E$ staining of SVZ (top) and DG (bottom) from 1-month-old $(\boldsymbol{A})$ and 6-month-old ( $\boldsymbol{B})$ WT and GD3S-KO mice. Lines indicate the boundaries of SVZ. Scale bars: $50 \mu \mathrm{m}$. C, Cellularity of the lateral SVZ from every $20 \mu \mathrm{m}$ section was measured. $\boldsymbol{D}$, Quantification of DG cellularity from every $20 \mu \mathrm{m}$ section of the dorsal hippocampus; $n=4$ pairs of mice, $>4$ sections per mouse brain were measured. Values are expressed as mean $\pm S E M$; ${ }^{* *} p<0.01$.
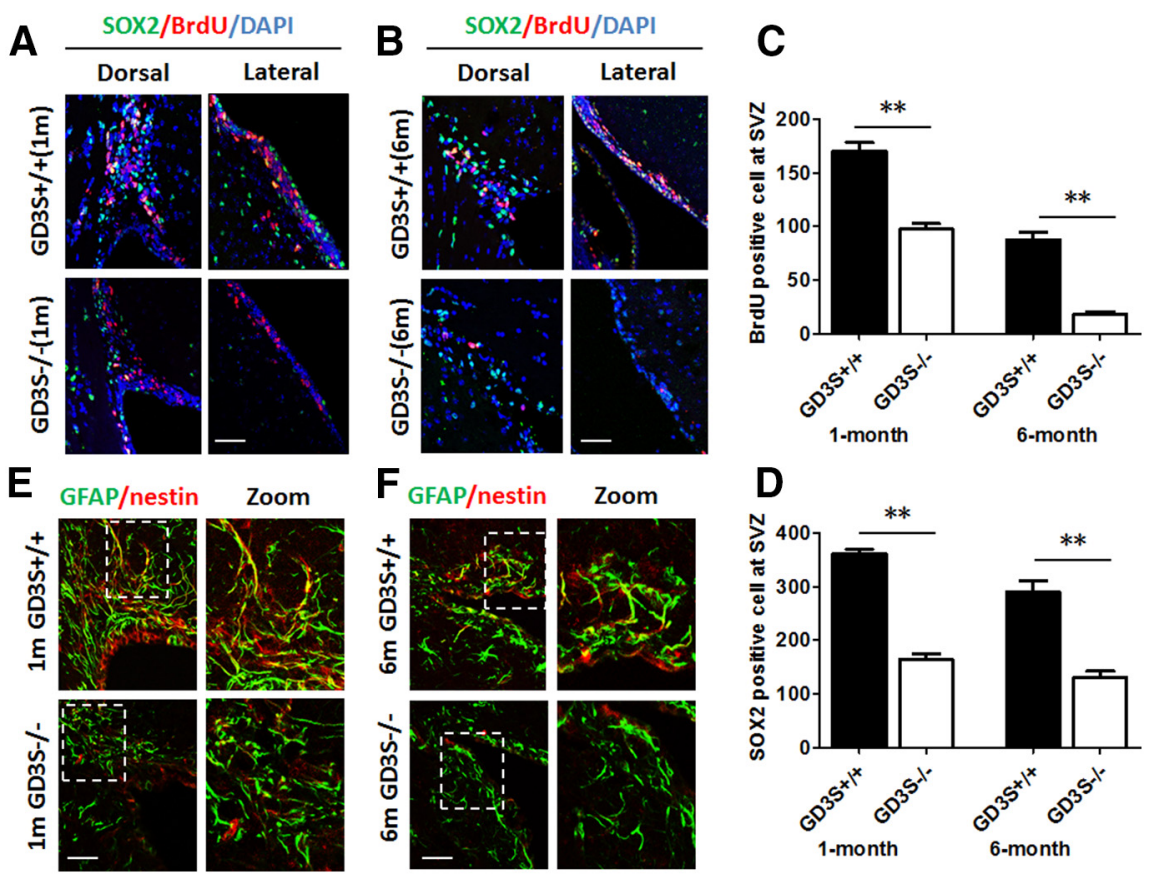

Figure 4. Progressive loss of NSC pool in the SVZ of GD3S-KO mice in adulthood. $A, B$, Immunofluorescence for SOX 2 and BrdU in the SVZ of BrdU-injected GD3S ${ }^{+/+}$and GD3S ${ }^{-/-}$mice. Representative parts of SVZ from one pair of 1-month-old mice $(A)$ and 6-month-old mouse brains $(\boldsymbol{B})$ are shown. $\boldsymbol{C}, \boldsymbol{D}$, Statistical results of the mean \pm SEM BrdU-positive $(\boldsymbol{C})$ and SOX2-positive $(\boldsymbol{D})$ cell at the SVZ ( $n=4$ pairs of mice, $>5$ sections per mouse were counted). $\boldsymbol{E}, \boldsymbol{F}$, Immunofluorescence for nestin and GFAP to examine the radial glia-like NSCs in SVZ. The right lanes are enlarged pictures showing more details in the inset. Scale bars: $20 \mu \mathrm{m}$. 
A

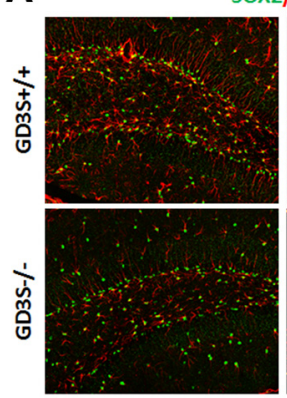

1-month old

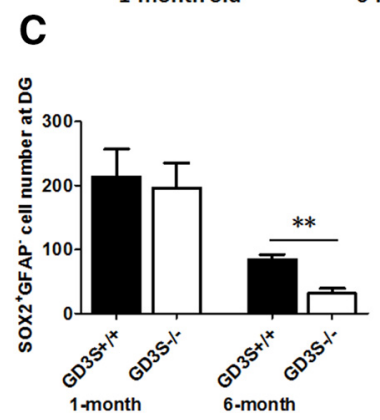

-month old

B

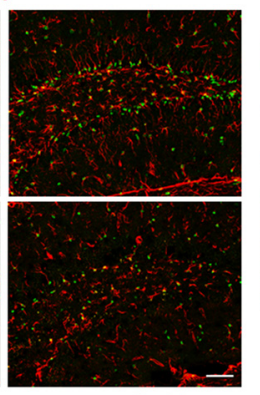

D GFAP/nestin
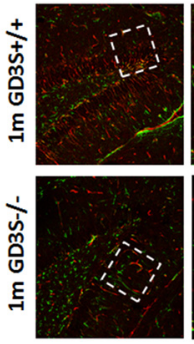

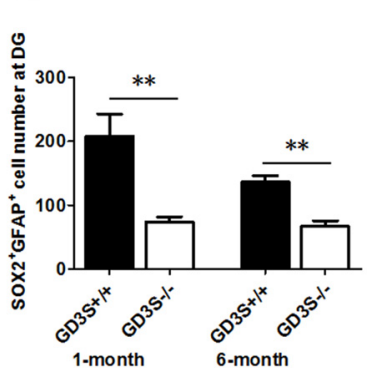

E GFAP/nestin

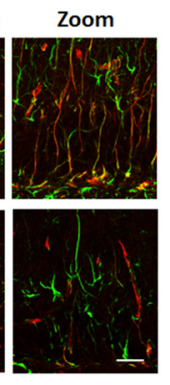

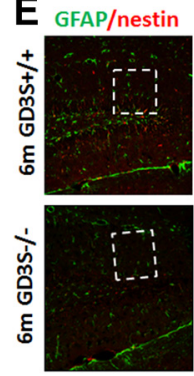

Figure 5. Progressive loss of the NSC pool in the DG of GD3S-K0 mice in adulthood. $A$, Representative sections of DG from 1-month-old (left) and 6-month-old (right) mouse brains stained with SOX2 and GFAP. B, C, Quantification of type 1 ( $B$, SOX2 and GFAP double positive) and type 2 (C, SOX2 positive and GFAP negative) NSCs at DG from every $20 \mu \mathrm{m}$ section of the dorsal hippocampus. D, E, Immunofluorescence for nestin and GFAP to examine the radial glia-like NSCs at the DG of 1-month-old (D) and 6-month-old $(\boldsymbol{E})$ mouse brain; $n=4$ pairs of mice, $>5$ sections per brain region were measured. Enlarged pictures showing more detail in the inset are placed on the right. Arrows indicating the nestin and GFAP double-positive radial glia-like NSCs. Scale bars: $20 \mu \mathrm{m}$.

A

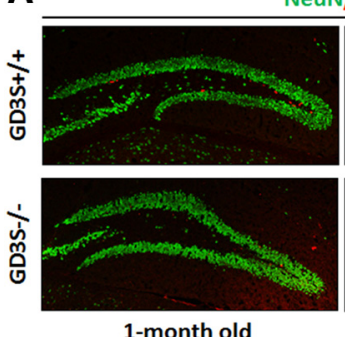

C

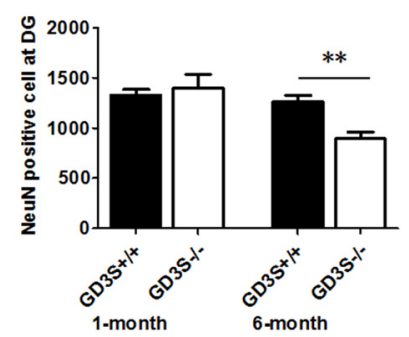

B

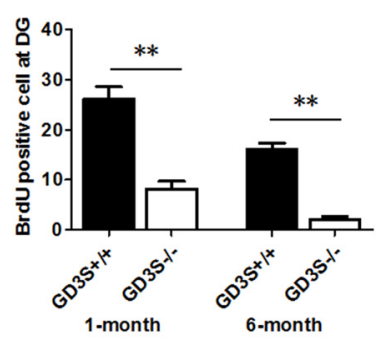

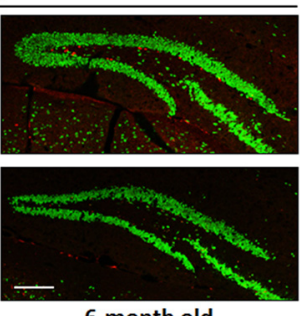

D

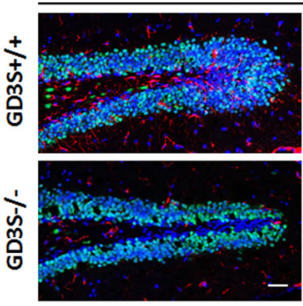

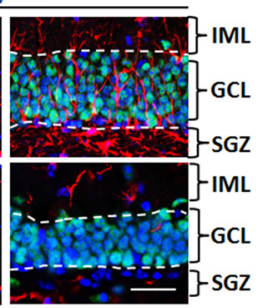

Figure 6. Decreased proliferating cell population and reduced $G C L$ at the DG ofDG3S-KO mice. $A$, Immunofluorescence for NeuN and BrdU at the DG of BrdU-injected 1-month-old (left) and 6-month-old (right) mice. B, C, Quantification of the BrdU-positive (B) and NeuN-positive $(\boldsymbol{C})$ cells at the DG from every $20 \mu \mathrm{m}$ section of the dorsal hippocampus; $n=4$ pairs of mice, $>5$ sections per mouse were counted. $\boldsymbol{D}$, Immunofluorescence for NeuN and GFAP at the DG of 6-month-old mice. Lines indicate the boundaries of $\mathrm{GCL}$. IML, inner molecular layer. Scale bars: $\boldsymbol{A}, 50 \mu \mathrm{m} ; \boldsymbol{D}, 20 \mu \mathrm{m}$.

nestin-expressing radial glia-like cells in the DG of 1-month-old GD3S-KO mouse brain indicated that the effect of GD3 for maintenance of the NSC population in the DG occurred at an early adult age. These results, together with the observations at the SVZ, suggested that the "quiescent" or "slow dividing" radial glia-like NSC population was the predominately reduced precur-

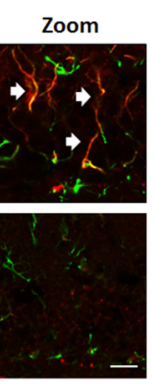

sor cell type in the GD3S-KO mouse brain. As shown by the in vivo clonal lineage tracing study, the nestin-expressing radial glia-like cells at the DG region were able to undergo self-renewal in the adult by either asymmetric or symmetric cell division, so that the NSC pool was maintained throughout the adult life (Bonaguidi et al., 2011). The GFAP-expressing radial glia-like progenitors are known to be the principal source of constitutive neurogenesis in postnatal and adult mice (Anthony et al., 2004; Garcia et al., 2004). Therefore, it is highly possible that the impaired self-renewal capacity of those radial glia-like cells in vivo should be responsible to the progressive reduction of the NSC pool in GD3S-KO mice. Furthermore the depletion of the NSC pool in the brain would lead to adult neurogenesis defects in older GD3S-KO mice.

\section{Impaired adult neurogenesis at SVZ and DG of GD3S-KO mice}

We then measured the proliferating cell population and mature granule neurons in the DG by the BrdU incorporation assay and NeuN staining. Results showed that the number of cells for short-term BrdU incorporation in DG was reduced in the GD3S-KO mice at both 1 month (GD3S-KO $8.1 \pm 1.6$ vs WT $26.2 \pm 2.4, p<0.01)$ and 6 months of age (GD3S-KO $2.0 \pm 0.7$ vs WT $16.2 \pm 1.2, p<0.01$; Fig. $6 A, B)$. When the number of mature neuronal cells was counted by NeuN staining, it showed that the number of NeuNpositive cells in 1-month-old mice had no significant difference between WT and GD3S-KO mice (GD3S-KO $2183.0 \pm 110.8$ vs WT $1939.0 \pm 163.5$, $p>0.05$; Fig. $6 A, C)$. In the 6 -monthold pairs, we noticed that the GCL at the DG was thinner (thickness of the GCL: GD3S-KO $32.7 \pm 0.9$ vs WT $43.2 \pm 0.8$ $\mu \mathrm{m}, p<0.01)$ in the GD3S-KO mice than in their age-matched WT littermates (Fig. 6D). The number of NeuNpositive cells was also reduced in the DG of GD3S-KO mice compared with their WT littermates (GD3S-KO 969.5 \pm 89.9 vs WT $1562.0 \pm 61.2, p<0.01$; Fig. $6 C, D)$. It is known that new granular neurons are continuously generated throughout life from the SGZ of DG (Bonaguidi et al., 2011). This result indicated that the decrease of newly generated neurons at the GCL of adult GD3S-KO mouse brain might result from an impaired adult neurogenesis in the DG. To confirm this notion, DCX staining was performed to label the immature granule neurons at the DG. Consistently, the DCX-positive cells at the DG were slightly reduced in the 
A
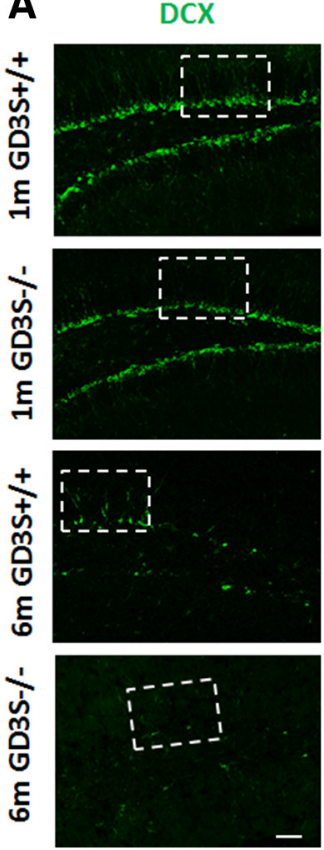
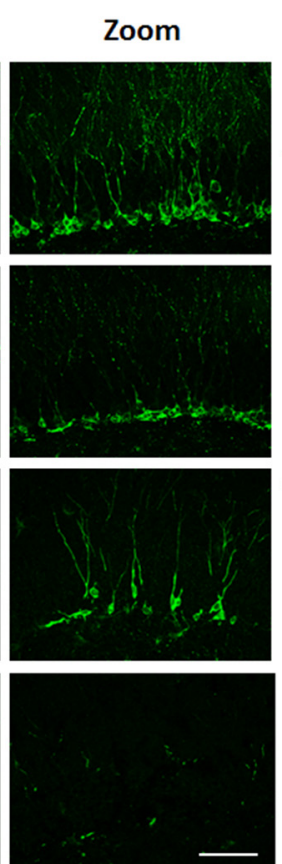

B
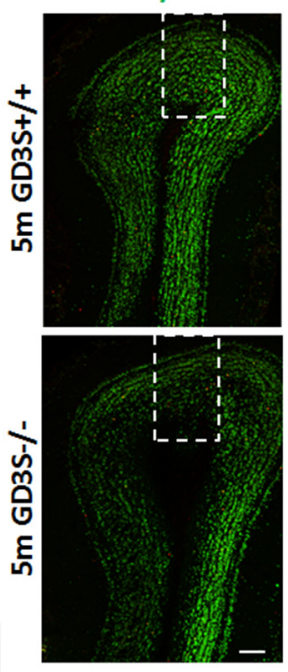

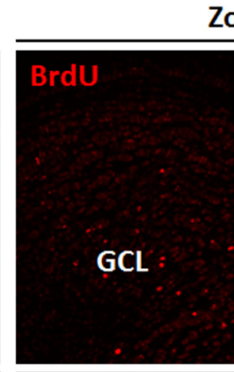

Zoom

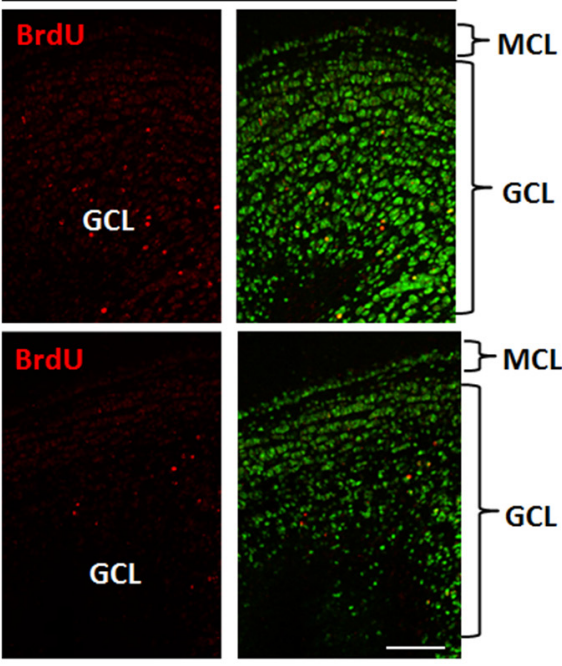

Figure 7. Decreased number of newly generated neurons at the DG and SVZ of DG3S-KO mice. $A, D C X$ immunostaining of the immature neurons at DG from 1- and 6-month-old mice. Note the pronounced decrease in the DCX-expressing cells in the 6-month-old GD3S-KO mice. $\boldsymbol{B}$, Long-term BrdU lineage tracing of the SVZ adult neurogenesis. Costaining of BrdU and NeuN in the olfactory bulb of 5-month-old mice at 4 weeks after BrdU injection. The zoomed areas are shown on the right. MCL, molecular cell layer. Scale bars: $20 \mu \mathrm{m}$.

1-month-old GD3S-KO mice compared with their WT littermates (Fig. 7A). In the 6-month-old mice, the DCX-positive cells were almost absent from the DG of the GD3S-KO mouse brain (Fig. 7A). As DCX has been recognized as a marker to label the authentic newly generated neurons in the adult DG (Rao and Shetty, 2004), these data provided convincing evidence that the progressive deletion of the NSC populations in the adult GD3S-KO mouse brain leads to impaired adult neurogenesis in these mice, which became more severe as the mice grew older.

To evaluate neurogenesis of the SVZ, long-term BrdU lineage tracing analyses were performed to label the newly generated neurons in this region. NSCs residing within the SVZ contribute to the long-term neurogenesis in the olfactory bulb. Neuroblasts originating from the SVZ migrate through the rostral migratory pathway with a time frame of 4 weeks to yield granular neurons in the olfactory bulb (Lledo and Saghatelyan, 2005). Therefore, the newly generated neurons in the olfactory bulb can be labeled with BrdU incorporation and subjected to lineage tracing at 4 weeks post incorporation. To perform this study, BrdU was administered to the 4-monthold mice intraperitoneally three times within $1 \mathrm{~d}$ at $4 \mathrm{~h}$ intervals, and then the BrdU-incorporated newborn neurons were detected by BrdU and NeuN costaining in the olfactory bulb 4 weeks later. Results showed that there were fewer long-term BrdU-incorporated cells within the GCL of the olfactory bulb of the GD3S-KO mice than in their WT littermates (GD3S-KO $43.6 \pm 1.7$ vs WT $77.4 \pm 1.8, p<0.01$; Fig. $7 B$ ). Meanwhile, the density of neurons in the GCL was much lower in the GD3S-KO mice (Fig. 7B) than in their WT littermates, which indicated a long-term insufficiency of the supply of new neurons to this region. Altogether, these results provided evidence that adult neurogenesis was impaired in the GD3S-KO mice at both the DG and SVZ, and supported the role of GD3 in maintaining the self-renewal capacity of NSCs both at the DG and SVZ in the adult ages.

The defective self-renewal and radial glia-like cell outgrowth of NSCs in postnatal GD3S-KO mice was rescued by transfection with ST-II-GFP

Collectively, all the in vivo data showed that the NSC pool, especially the radial glia-like cell population, was largely depleted in the adult GD3S-KO mouse brain. To further study the role of GD3 in postnatal NSC self-renewal and radial glia-like cell out growth, we examined NSC cultures prepared from P10 WT and GD3S-KO pups. Consistent with our previous findings, NSCs prepared from GD3S-KO pups failed to form neurospheres in the secondary passage; instead, irregularly shaped clusters were found to attach to the bottom of the Petri dish (Fig. 8A). When the neurospheres from the WT pups were seeded onto PLO- and fibronectin-coated plates, they grew with a radial-shaped morphology, showing outgrowth of radial glia-like cells from the center to the periphery (Fig. $8 B$ ). Immunostaining showed that most of these radial glia-like cells coexpressed GFAP and nestin, indicating that they are the radial glia-like stem cells in the in vitro cultures (Fig. 8E). However, when the clusters from the GD3S-KO were grown on PLO- and fibronectin-coated plates, they appeared with an irregular morphology with very few of the radial glia-like cells among the cell populations (Fig. $8 B$ ). Immunostaining confirmed that no GFAP and nestin double-positive cells were detected among these cells (Fig. 8E), and the GFAPpositive cells did not show a radial glia-like morphology (Fig. 8E). These results demonstrated a defect of radial glia-like cell outgrowth from NSCs cultured from postnatal GD3S-KO mice, which corroborated our in vivo results.

We next tested whether restoration of GD3 expression in the GD3S-KO NSCs could rescue the ability for neurosphere formation and correct the defect for radial glia-like cell outgrowth. By 
A

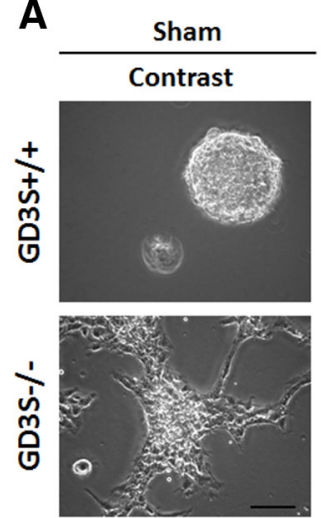

B
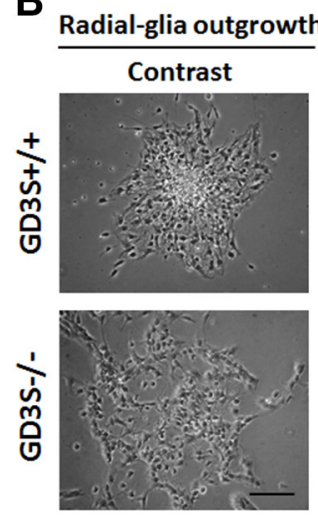

C

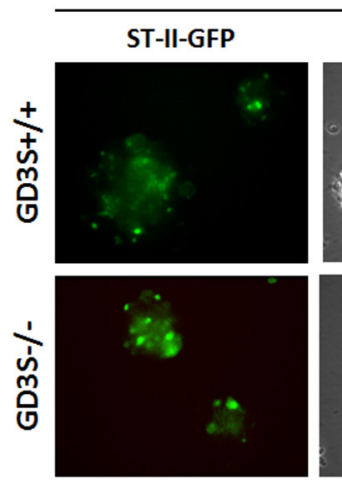

E

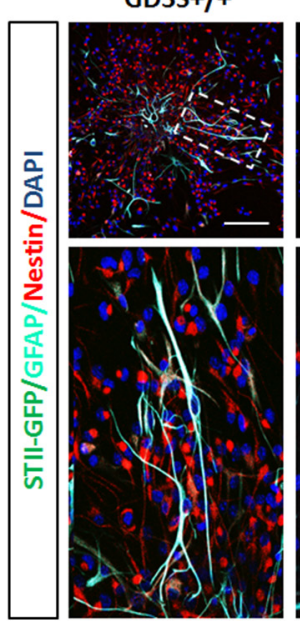

ST-II-GFP transfected

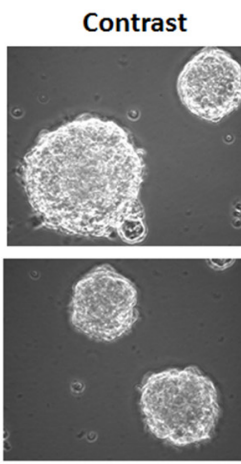

GD3S-/-

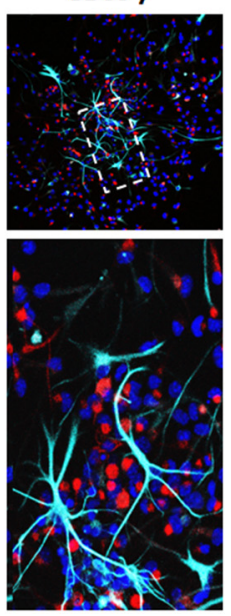

D GD3/ ST-II-GFP

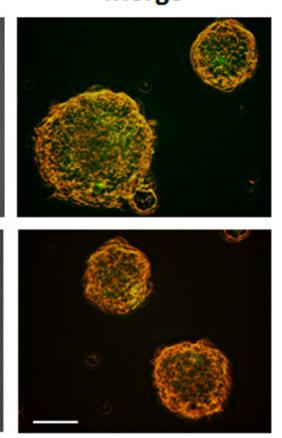

$F$

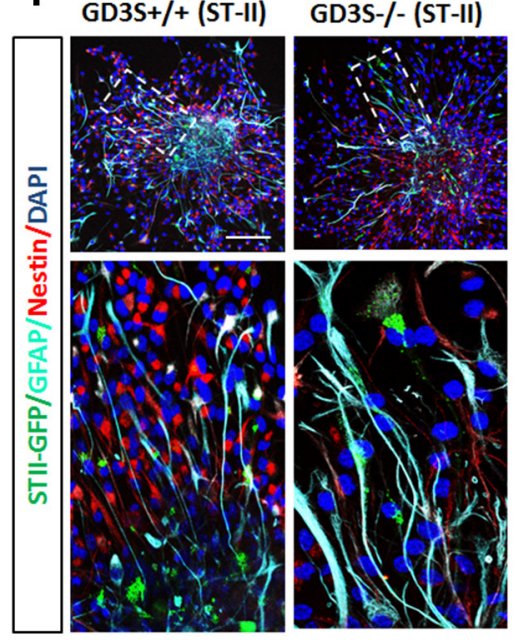

Figure 8. Rescue effects of exogenous ST-II-GFP transfection to the NSCs from postnatal GD3S-K0 mice on their defective self-renewal capability and radial glia-like cell outgrowth. $\boldsymbol{A}$, Impaired self-renewal capacity of the postnatal (P10) GD3S-KO NSCs shown by the secondary neurosphere-forming assay. $\boldsymbol{B}$, NSCs from postnatal GD3S-K0 mice failed to have radial glia-like cells growing out on the PLO- and fibronectin-coated surface. C, Exogenous transfection of the p-ST-II-GFP-N1 rescued the self-renewal defects in the GD3S-KO NSCS. D, Exogenous transfection of the p-ST-II-GFP-N1 re-established the GD3 expression in the GD3S-KO NSCs. Arrows indicating the cells with transfected p-ST-II-GFP-N1 (green) are GD3 positive (red); arrowheads showing the cells without transfected p-ST-II-GFP-N1 are GD3 negative. $\boldsymbol{E}, \boldsymbol{F}$, Nestin and GFAP costaining of the radial glia-like cells from the WT and GD3S-KO NSC without $(\boldsymbol{E})$ or with $(\boldsymbol{F})$ p-ST-II-GFP-N1 transfection. Zoomed areas are shown in the bottom. Scale bars: $\boldsymbol{A}-\boldsymbol{C}, \boldsymbol{E}, \boldsymbol{F}, 20 \mu \mathrm{m} ; \boldsymbol{D}, 10 \mu \mathrm{m}$.

exogenous transfection of cells with a GD3-synthase gene fusion plasmid p-ST-II-GFP-N1, the expression of GD3 in GD3S-KO NSCs was effectively restored $24 \mathrm{~h}$ after transfection, as confirmed by immunostaining with anti-GD3 mAb R24 (Fig. 8D). When the ST-II-transfected NSCs were grown as floating cells in NSC culture medium, neurospheres were nicely formed in both WT and GD3S-KO groups (Fig. 8C). On PLO- and fibronectincoated plates, those spheres grew in a radial-shaped morphology and the radial glia-like cells were detected to be GFAP and nestin double positive (Fig. $8 F$ ). These findings further support the role for ganglioside GD3 in the self-renewal of NSCs and outgrowth of radial glia-like NSCs in vitro and in vivo, and both events are crucial for the maintenance of the NSC pool and neurogenesis in the postnatal and adult brain.

GD3S-KO mice showed increased depression-like behaviors Over the past few years, mounting evidence has been generated to support the critical contribution of adult-born neurons to the function of the olfactory bulb and hippocampus (Zhao et al., 2008). To test whether the GD3S-KO mice had any behavioral changes that were related to neurogenesis defects, several hippocampus-dependent functional tests were performed on the adult (4- to 6-month-old) GD3S-KO mice and their WT littermates. Decreased adult neurogenesis has been implicated as a potential mechanism for the etiology of depression and anxiety (Snyder et al., 2011). "Behavioral despair" is a hallmark symptom of depression, and presents as loss of hope to escape the stressful environment in rodents. The TST and FST are two common tests used for evaluating depression-like behaviors in mice. A lack of escape-related behavior is considered immobility, which is used as a measure of behavior despair.

In the TST, we compared the immobility time and the latency to become immobile in the GD3S-KO mice and their WT littermates. Results showed that the latency to become immobile is decreased in GD3S-KO mice (GD3S-KO $12.3 \pm 1.9 \mathrm{~s}$ vs WT $18.8 \pm 1.9 \mathrm{~s} ; p<0.05$; Fig. $9 A$ ), while the total immobility time was markedly increased in GD3S-KO mice compared with their WT littermates (GD3S-KO $244.1 \pm 10.1$ vs WT $118.2 \pm 12.0 \mathrm{~s}$; $p<0.01$; Fig. 9B). These results indicate that the adult GD3S-KO mice show the lack of escape-related behaviors under normal conditions.

To further confirm the results from the TST, we compared the immobility time and the latency to become immobile between the GD3S-KO mice and their WT littermates in the FST. Results showed that during the $6 \mathrm{~min}$ of measurement, the GD3S-KO mice had decreased latency to become immobile (GD3S-KO $48.4 \pm 4.7$ vs WT $25.6 \pm 3.3 \mathrm{~s} ; p<0.01$ ) and increased immobility time (GD3S-KO $186.1 \pm 19.3$ vs WT 
$38.3 \pm 16.4 \mathrm{~s} ; p<0.01)$ compared with their WT littermates (Fig. 9C). These results are consistent with those from TST and demonstrated that GD3S-KO mice displayed a depression-like behavior, altogether the observations from behavioral studies indicated that GD3 deficiency could cause depression-like behaviors in adulthood, and those behavioral changes were likely co-related to the defective adult neurogenesis in those mice.

\section{Discussion}

Gangliosides are ubiquitously found in mammalian tissues, and are most abundantly expressed in the nervous system, where their occurrence is cell specific and developmentally regulated (Ngamukote et al., 2007). Among the many ganglioside species, GD3 is first found to be highly expressed in immature neuroectodermal cells (Goldman et al., 1984), and later is considered to be an NSC marker (Nakatani et al., 2010). The histological expression profile of GD3 detected here in the SVZ and DG of postnatal mouse brain is consistent with previous findings in postnatal rat brain (Goldman et al., 1984). Other b-series gangliosides, such as GD2, GT1b, and GQ1b, have also been reported to be expressed in neuroepithelial cells (Yanagisawa et al., 2005). The GD3S-KO mice were generated by genetically knocking out the GD3synthase gene (also known as ST8SIA1, GM3: $\alpha 2,8$-sialyltransferase, ST-II, or Sial-T2) from the chromosome (Okada et al., 2002). Therefore, all the b-series gangliosides, including GD3, GD2, GD1b, GT1b, and GQ1b, are absent in the GD3S-KO mouse brains. It was initially reported that these GD3S-KO mice with b-series ganglioside deficiency exhibited no definite changes in neurogenesis, but showed impaired regeneration of the lesioned hypoglossal nerve (Okada et al., 2002). This claim, however, received increasing skepticism as the initial studies were mainly performed by comparing the gross histological structures of the brains. The NSC population and the adult neurogenesis capacity in the GD3S-KO mice have never been thoroughly studied.

By examining the NSCs cultures in vitro, however, we noticed that the loss of self-renewal capacity in the GD3S-KO NSCs was more obvious with further passages (Wang and $\mathrm{Yu}, 2013$ ). These observations imply that GD3 plays a crucial role in extension of NSC division during development and maturation of the CNS. The GD3S-KO mice provided us with an excellent loss-offunction model to study the physiological roles of the b-series gangliosides, particularly GD3, in vivo. In this study, the progressive reduction of the NSC pool observed in the adult GD3S-KO mouse brain is consistent with our in vitro findings. The decreased granule neurons in the GCL of DG and olfactory bulb of adult mice indicated that depletion of the NSC pool caused by loss of b-series gangliosides compromised the brain functions with aging. The late onset of the neuronal loss in the GD3S-KO mice may be explained by the time window required for postnatal 0.01 .
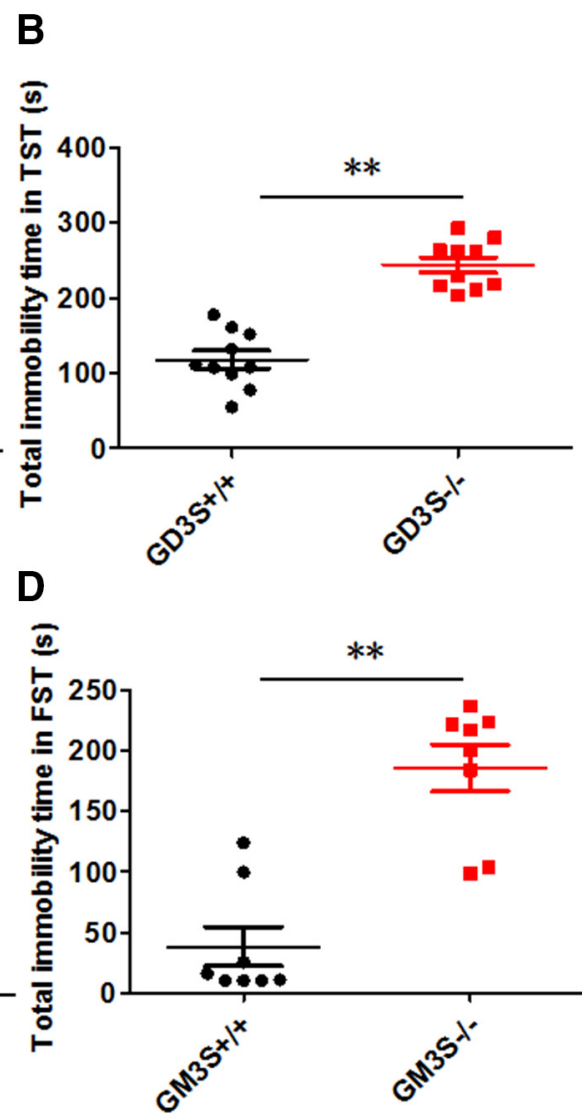

Figure 9. Depression-like behaviors of adult GD3S-KO mice in TST and FST. $\boldsymbol{A}$, In the TST, the GD3S-KO mice showed decreased time in the TST. $\boldsymbol{C}$, In the FST, the GD3S-KO mice showed decreased time latency to become immobile compared with their WT littermates. $\boldsymbol{D}$, The total immobility time in the FST was increased in the GD3S-KO mice; $n=9-10$ per group, ${ }^{*} p<0.05$; ${ }^{* *} p<$

NSCs and other neural progenitor cells to become exhausted and the gradual depletion of the NSC pool in the GD3S-KO mouse brains.

NSCs are characterized by their ability to proliferate, selfrenew, and differentiate into multiple neural cell types, such as neurons, astrocytes, and oligodendrocytes (Gage, 2000). The adult neurogenesis must be maintained in a finely regulated manner, in which the number of quiescent stem cells and the newly generated neurons and astrocytes can be kept strictly under control. Both intrinsic and extrinsic mechanisms are involved in fate determination of NSCs. Several extrinsic factors, such as Notch (Imayoshi et al., 2010), bone morphogenetic proteins (Lim et al., 2000), and sonic hedgehog (Ahn and Joyner, 2005), have been found to regulate the fate determination of adult neural precursor cells. Growth factors and neurotrophins, such as FGF2, EGF (Kuhn et al., 1997), IGF-2 (Lehtinen et al., 2011), and BDNF (Waterhouse et al., 2012) have also been identified to be regulators of adult neurogenesis. However, it is still not clear how the extrinsic factors are regulated by environmental stimuli and coupled to the intrinsic signaling.

The localization of gangliosides on the outer surface of cell plasma membranes raised the intriguing possibility that gangliosides containing microdomains in the plasma membrane may be associated with various growth factor receptors to regulate the biological processes of cells. In fact, a number of growth factor receptors have been described to be regulated by gangliosides (Miljan and Bremer, 2002). Interactions of gangliosides with 
growth factor receptors have also been reported in a number of studies (de Laurentiis et al., 2007), and these interactions have been recognized as regulators of the related signaling pathways. Recently, we have provided direct evidence that the GD3containing microdomains act as a platform to initiate and facilitate the EGF signaling in cultured NSCs. GD3 was found to interact with EGF receptors and promote their recycling to the plasma membrane surface after endocytosis, so that the proliferation and self-renewal signaling of NSCs could be efficiently maintained (Wang and Yu, 2013). Interestingly, upregulation of GD3-synthase has also been found to enhance the proliferation of tumor cells through growth factor receptor signaling (Cazet et al., 2010), and is suggested to be expressed in cells with high metabolic activity by early studies (Seyfried and Yu, 1985). This is consistent with our finding that GD3 has an effect on the proliferation and self-renewal of NSCs. Based on the current study and reports from other laboratories, it is reasonable to propose that GD3 may act as an important mediator on the NSC surface membrane, through which extrinsic growth factors communicate with the intrinsic signaling network to regulate the proliferation and self-renewal of NSCs. Under in vivo conditions, it is clear that every stage of neurogenesis can be regulated by one or more different environmental stimuli, and multiple extracellular players may act concurrently on different phases of adult neurogenesis (Ming and Song, 2011). Further studies are still needed to determine the effective extrinsic growth factors responsible for the maintenance of the adult NSC pool under different conditions, and to clarify how and with what these growth factor receptors and gangliosides are associated to affect cellular growth and differentiation.

It is noteworthy that the GD3S-KO caused a progressive depletion of the postnatal NSC pool, but only showed minor, subtle effects on embryonic neurogenesis. This is consistent with the apparent normal size and structure of the postnatal GD3S-KO mouse brain reported by Okada et al. (2002). An alternative possible explanation for this phenomenon could be the compensatory effects of other series of gangliosides during brain development. It has been shown that deletion of b-series gangliosides leads to an increased amount of a-series gangliosides, especially GM3, in embryonic brain (Okada et al., 2002). The accumulation of GM3, which is detected in very early (E10-E12) embryonic stages but not in late (after E15) embryonic development and adult ages (Ngamukote et al., 2007), may play a compensatory role for GD3 during early developmental stages of brain. Whether the GM3 or other gangliosides are playing a compensatory role here needs further investigation. Nevertheless, the compensatory effects of other gangliosides are not efficient to replace the role of the b-series gangliosides, and this incomplete effect may lead to a late onset of neurogenesis defects in the GD3S-KO mice. It should also be noted that the self-renewal ability of NSCs obtained from embryonic (E14) GD3S-KO mice also requires several passages to become exhausted in in vitro cultures (Wang and Yu, 2013). Therefore, we speculate that the expression of GD3 is essential for the maintenance, rather than the generation, of NSCs in developing brain. The self-renewal and maintenance of the postnatal NSC population is crucial to adult neurogenesis in the mouse brain. Thus, neurogenesis defects could be observed only in late postnatal and adult mice because of the time window for the deletion of NSCs from the original NSC pool generated in the embryonic brain. Another possibility is that there may be certain "niche" factors for adult neurogenesis that are specifically regulated by the expression of b-series gangliosides. It would be intriguing to characterize those candidate niche factors and their roles in adult neurogenesis by interacting with $\mathrm{b}$-series gangliosides in the future.

The continuous depletion of the NSC pool and reduction of neurogenesis during the aging process has been reported in both adult SGZ and SVZ (Rossi et al., 2008; Encinas et al., 2011). However, several lines of evidence showed that the GFAPexpressing radial glia-like cells are in fact the NSCs in postnatal and adult brain, and provide the principal source for constitutive neurogenesis in adult brains (Garcia et al., 2004; Bonaguidi et al., 2011). This concept has also been supported by recent fatemapping studies in mice using inducible Cre recombinase driven by GFAP, GLAST, and nestin promoters (Dhaliwal and Lagace, 2011). Results from our in vivo study showed that the quiescent nestin and GFAP double-positive cells were the predominant depleted NSC population in the GD3S-KO brain. Therefore, it is very likely that deficits of the self-renewal capacity in this type of NSC may be contributing to the defects of neurogenesis in GD3S-KO mice. It is also interesting to note the correlation between the reduced expression level of GD3 and the increased age of the WT mice detected by immunostaining of GD3 (Fig. 1). Although it is still not clear how the GD3 expression level is regulated during aging, our findings raise the intriguing possibility that the neurogenesis potential of the adult brain might be modulated by manipulating the levels of gangliosides, including GD3. Further studies in this field will shed light on neuronal repair and neuroregeneration under disease conditions by promoting adult neurogenesis.

\section{References}

Ahn S, Joyner AL (2005) In vivo analysis of quiescent adult neural stem cells responding to Sonic hedgehog. Nature 437:894-897. CrossRef Medline

Aimone JB, Deng W, Gage FH (2011) Resolving new memories: a critical look at the dentate gyrus, adult neurogenesis, and pattern separation. Neuron 70:589-596. CrossRef Medline

Allen JA, Halverson-Tamboli RA, Rasenick MM (2007) Lipid raft microdomains and neurotransmitter signalling. Nat Rev Neurosci 8:128-140. CrossRef Medline

Alonso M, Viollet C, Gabellec MM, Meas-Yedid V, Olivo-Marin JC, Lledo PM (2006) Olfactory discrimination learning increases the survival of adult-born neurons in the olfactory bulb. J Neurosci 26:10508-10513. CrossRef Medline

Anthony TE, Klein C, Fishell G, Heintz N (2004) Radial glia serve as neuronal progenitors in all regions of the central nervous system. Neuron 41: 881-890. CrossRef Medline

Bonaguidi MA, Wheeler MA, Shapiro JS, Stadel RP, Sun GJ, Ming GL, Song H (2011) In vivo clonal analysis reveals self-renewing and multipotent adult neural stem cell characteristics. Cell 145:1142-1155. CrossRef Medline

Buffo A, Rite I, Tripathi P, Lepier A, Colak D, Horn AP, Mori T, Götz M (2008) Origin and progeny of reactive gliosis: a source of multipotent cells in the injured brain. Proc Natl Acad Sci U S A 105:3581-3586. CrossRef Medline

Cazet A, Lefebvre J, Adriaenssens E, Julien S, Bobowski M, Grigoriadis A, Tutt A, Tulasne D, Le Bourhis X, Delannoy P (2010) GD(3) synthase expression enhances proliferation and tumor growth of MDA-MB-231 breast cancer cells through c-Met activation. Mol Cancer Res 8:1526-1535. CrossRef Medline

de Laurentiis A, Donovan L, Arcaro A (2007) Lipid rafts and caveolae in signaling by growth factor receptors. Open Biochem J 1:12-32. CrossRef Medline

Dhaliwal J, Lagace DC (2011) Visualization and genetic manipulation of adult neurogenesis using transgenic mice. Eur J Neurosci 33:1025-1036. CrossRef Medline

Doetsch F, Caillé I, Lim DA, García-Verdugo JM, Alvarez-Buylla A (1999) Subventricular zone astrocytes are neural stem cells in the adult mammalian brain. Cell 97:703-716. CrossRef Medline

Encinas JM, Michurina TV, Peunova N, Park JH, Tordo J, Peterson DA, Fishell G, Koulakov A, Enikolopov G (2011) Division-coupled astro- 
cytic differentiation and age-related depletion of neural stem cells in the adult hippocampus. Cell Stem Cell 8:566-579. CrossRef Medline

Gage FH (2000) Mammalian neural stem cells. Science 287:1433-1438. CrossRef Medline

Garcia AD, Doan NB, Imura T, Bush TG, Sofroniew MV (2004) GFAPexpressing progenitors are the principal source of constitutive neurogenesis in adult mouse forebrain. Nat Neurosci 7:1233-1241. CrossRef Medline

Goldman JE, Hirano M, Yu RK, Seyfried TN (1984) GD3 ganglioside is a glycolipid characteristic of immature neuroectodermal cells. J Neuroimmunol 7:179-192. CrossRef Medline

Hakomori S, Handa K, Iwabuchi K, Yamamura S, Prinetti A (1998) New insights in glycosphingolipid function: "glycosignaling domain," a cell surface assembly of glycosphingolipids with signal transducer molecules, involved in cell adhesion coupled with signaling. Glycobiology 8:xi-xix. CrossRef Medline

Imayoshi I, Sakamoto M, Yamaguchi M, Mori K, Kageyama R (2010) Essential roles of Notch signaling in maintenance of neural stem cells in developing and adult brains. J Neurosci 30:3489-3498. CrossRef Medline

Kuhn HG, Dickinson-Anson H, Gage FH (1996) Neurogenesis in the dentate gyrus of the adult rat: age-related decrease of neuronal progenitor proliferation. J Neurosci 16:2027-2033. Medline

Kuhn HG, Winkler J, Kempermann G, Thal LJ, Gage FH (1997) Epidermal growth factor and fibroblast growth factor-2 have different effects on neural progenitors in the adult rat brain. J Neurosci 17:5820-5829. Medline

Lehtinen MK, Zappaterra MW, Chen X, Yang YJ, Hill AD, Lun M, Maynard T, Gonzalez D, Kim S, Ye P, D’Ercole AJ, Wong ET, LaMantia AS, Walsh CA (2011) The cerebrospinal fluid provides a proliferative niche for neural progenitor cells. Neuron 69:893-905. CrossRef Medline

Lim DA, Tramontin AD, Trevejo JM, Herrera DG, García-Verdugo JM, Alvarez-Buylla A (2000) Noggin antagonizes BMP signaling to create a niche for adult neurogenesis. Neuron 28:713-726. CrossRef Medline

Lledo PM, Saghatelyan A (2005) Integrating new neurons into the adult olfactory bulb: joining the network, life-death decisions, and the effects of sensory experience. Trends Neurosci 28:248-254. CrossRef Medline

Malatesta P, Hack MA, Hartfuss E, Kettenmann H, Klinkert W, Kirchhoff F, Götz M (2003) Neuronal or glial progeny: regional differences in radial glia fate. Neuron 37:751-764. CrossRef Medline

Merkle FT, Tramontin AD, García-Verdugo JM, Alvarez-Buylla A (2004) Radial glia give rise to adult neural stem cells in the subventricular zone. Proc Natl Acad Sci U S A 101:17528-17532. CrossRef Medline

Miljan EA, Bremer EG (2002) Regulation of growth factor receptors by gangliosides. Sci STKE 2002:re15. Medline

Ming GL, Song H (2011) Adult neurogenesis in the mammalian brain: significant answers and significant questions. Neuron 70:687-702. CrossRef Medline
Nakatani Y, Yanagisawa M, Suzuki Y, Yu RK (2010) Characterization of GD3 ganglioside as a novel biomarker of mouse neural stem cells. Glycobiology 20:78-86. CrossRef Medline

Ngamukote S, Yanagisawa M, Ariga T, Ando S, Yu RK (2007) Developmental changes of glycosphingolipids and expression of glycogenes in mouse brains. J Neurochem 103:2327-2341. CrossRef Medline

Okada M, Itoh Mi M, Haraguchi M, Okajima T, Inoue M, Oishi H, Matsuda Y, Iwamoto T, Kawano T, Fukumoto S, Miyazaki H, Furukawa K, Aizawa S, Furukawa K (2002) b-series Ganglioside deficiency exhibits no definite changes in the neurogenesis and the sensitivity to Fas-mediated apoptosis but impairs regeneration of the lesioned hypoglossal nerve. J Biol Chem 277:1633-1636. CrossRef Medline

Rao MS, Shetty AK (2004) Efficacy of doublecortin as a marker to analyse the absolute number and dendritic growth of newly generated neurons in the adult dentate gyrus. Eur J Neurosci 19:234-246. CrossRef Medline

Rossi DJ, Jamieson CH, Weissman IL (2008) Stems cells and the pathways to aging and cancer. Cell 132:681-696. CrossRef Medline

Seri B, García-Verdugo JM, McEwen BS, Alvarez-Buylla A (2001) Astrocytes give rise to new neurons in the adult mammalian hippocampus. J Neurosci 21:7153-7160. Medline

Seyfried TN, Yu RK (1985) Ganglioside GD3: structure, cellular distribution, and possible function. Mol Cell Biochem 68:3-10. Medline

Snyder JS, Soumier A, Brewer M, Pickel J, Cameron HA (2011) Adult hippocampal neurogenesis buffers stress responses and depressive behaviour. Nature 476:458-461. CrossRef Medline

Suh H, Consiglio A, Ray J, Sawai T, D’Amour KA, Gage FH (2007) In vivo fate analysis reveals the multipotent and self-renewal capacities of Sox $2+$ neural stem cells in the adult hippocampus. Cell Stem Cell 1:515-528. CrossRef Medline

Wang J, Yu RK (2013) Interaction of ganglioside GD3 with an EGF receptor sustains the self-renewal ability of mouse neural stem cells in vitro. Proc Natl Acad Sci U S A 110:19137-19142. CrossRef Medline

Waterhouse EG, An JJ, Orefice LL, Baydyuk M, Liao GY, Zheng K, Lu B, Xu B (2012) BDNF promotes differentiation and maturation of adult-born neurons through GABAergic transmission. J Neurosci 32:14318-14330. CrossRef Medline

Yanagisawa M, Taga T, Nakamura K, Ariga T, Yu RK (2005) Characterization of glycoconjugate antigens in mouse embryonic neural precursor cells. J Neurochem 95:1311-1320. CrossRef Medline

Yu RK, Nakatani Y, Yanagisawa M (2009) The role of glycosphingolipid metabolism in the developing brain. J Lipid Res [50 Suppl]:S440-S445. CrossRef Medline

Zhao C, Teng EM, Summers RG Jr, Ming GL, Gage FH (2006) Distinct morphological stages of dentate granule neuron maturation in the adult mouse hippocampus. J Neurosci 26:3-11. CrossRef Medline

Zhao C, Deng W, Gage FH (2008) Mechanisms and functional implications of adult neurogenesis. Cell 132:645-660. CrossRef Medline 